\title{
Land Subsidence of Kanto Plain Detection Using JERS-1 SAR Interferometry
}

\author{
Yanyan Agustian, Fuad Hasan*, Raden Herdian Bayu Ash Siddiq \\ Department of Civil Engineering, Widyatama University, Indonesia
}

Copyright $\subseteq 2019$ by authors, all rights reserved. Authors agree that this article remains permanently open access under the terms of the Creative Commons Attribution License 4.0 International License

\begin{abstract}
Since InSAR technique has a capability to detect a small surface elevation changes over large area, InSAR system has been used widely for good resolution mapping and other applications on various applied sciences. InSAR imagery is applied to investigate surface change and result detailed maps of contour, which help to detect disaster areas. This research is aimed to estimate the land subsidence using the differential interferometric synthetic aperture radar (InSAR). The research object is located in the west part of Japan, Kanto Plain area, where ground water actively is being extracted in quite large scale and produces centimeters of subsidence every year. Over the analyzed area, the surface deformation was detected and it was only related to subsidence process. In other words, there is no surface arising or uplift of surface. It signed by color phase changes correspond from zero to minus values.
\end{abstract}

Keywords InSAR, Kanto, Land Subsidence, Surface Deformation

\section{Introduction}

Interferomtric SAR technique was advanced for measurement of surface at multiple times[1]. The works of InSAR for topographic mapping is quite the same in principle to the approach of conventional stereoscopic. For stereoscopy, two displaced imaging positions are taken for a pair of terrain images. The field movement allows the restoration of topography because of parallax, at different heights are moved relatively to each other in the two images by an amount consecutive to their altitudes [2].

The Japan Earth Resources Satellite (JERS-1) was expedited in February 1992, into a 570-km, sun-synchronous orbit. It was launched from Japan Aerospace Exploration Agency (NASDA) Tanegashima Space Center with a iterative period of 44 days by the H-I launch vehicle at an altitude of $568 \mathrm{~km}$ into a solar-synchronous sub-recurrent orbit on February 11, 1992, and continuously observing and collecting data with a mission data recorder by the high performance Synthetic Aperture Sensor (OPS).

The mechanism of JERS-1 SAR Interferometry has explained by Tobita (2003) particularly. For two-pass method of detecting surface displacement, the phase is

$$
\phi_{2 \text { pass }}=\phi_{\text {flat }}-\phi_{\text {flat }, \text { sim }}=\frac{4 \pi}{\lambda} \Delta \rho
$$

Where $\varphi_{\text {flat }}=$ flattened phase

$\Phi_{\text {flat,sim }}=$ simulated phase from flettened phase and DEM If surface is not change, the simulated phase $\phi_{\text {flat,sim }}$ removes topographic phase variations, so $\phi_{2 \text { pass }}$ will be one constant color. Sensitivity of JERS-1 to surface change is represented by:

$$
\Delta \rho_{2 \pi}=\frac{\lambda}{2}
$$

where $\Delta \rho_{2} \pi$ denotes range difference per one cycle. Thus, interferometry phase is far more sensitive to surface displacement.

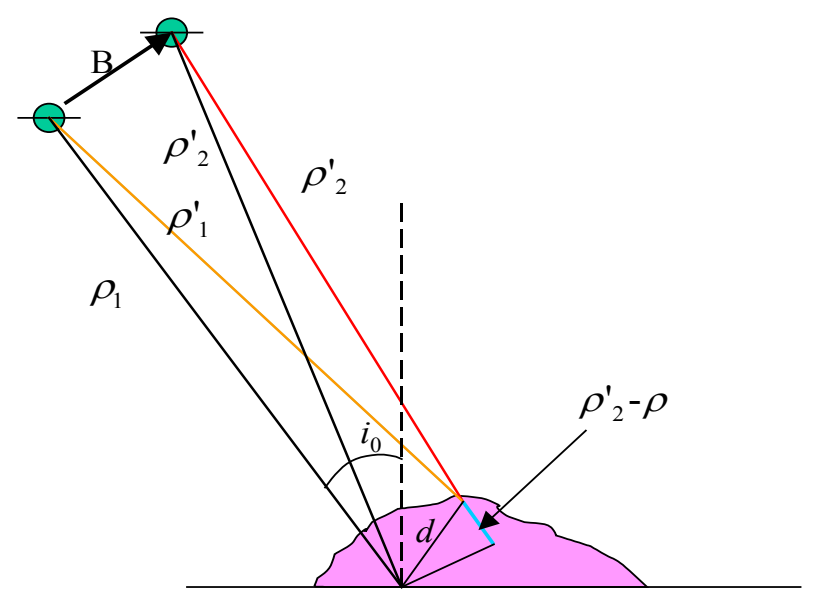

Figure 1. Geometry of height measurement by interferometric SAR [3] 
In principle, interferometry can be understand in view of the signal return of elemental scatterers then by comprising InSAR image on each resolution element. A resolution element can be defined as a complex phasor of the coherent backscatter from the scattering elements on the surface and the phase delay of propagation [4].

The interferometric phase is proportionally to the range difference from two antenna locations to a point in the ground subjected. This range difference can be stated in term of the vector distance the locations of two antenna, called the interferometric baseline. The range and azimuth position of the sensor associated with imaging a prone scatterer depends on the part of the synthetic aperture used on processing the image. Therefore, the interferometric baseline which is depends on the parameters of processing, can be understand as the difference between the location of the phase center vectors of two antenna at the time when a prone scatterer.

\section{Method Analyses}

The standard SAR processing procedures was followed to analyses all SAR data. Here, it is the major steps in interferometric processing those followed in this research.

1). Range and azimuth compression, which make compression of expanded signals in both range and azimuth directions into a point signal. Fourier transformation is adopted for the compression that is usually carried out to achieve convolution of received signals and a reference function.

2). Coreregistration between master and slave image, is the mechanism of adjusting up two images, then called master image and a slave image, layering the same area in a way that they fit exactly covering between master and slave image.

3). Radar image simulation is a technique that is based on the map of real field situation or image sensing materials or the reality radar image in accordance to the image processing of radar image in order to have the different frequency wavelength polarimetric ways radar images which are perform to removal the topographic fringes.

4). Phase unwapping, is the process of removal the modulo-2 $\pi$ uncertainty before topography estimation or land movement.

5). Differential InSAR. Since mostly repeated - track observations, which the track of the sensor does not repeat itself exactly, so the interferometric time-separated measurements generally consist the signature of topography and the radial movement, surface displacement. "Differential InSAR" is conceptually referred to the approach for reducing time separated measurements into velocity or surface movement by removing topography.

6). Geocoding is a process of the transformation between local coordinate system and global cartesian.

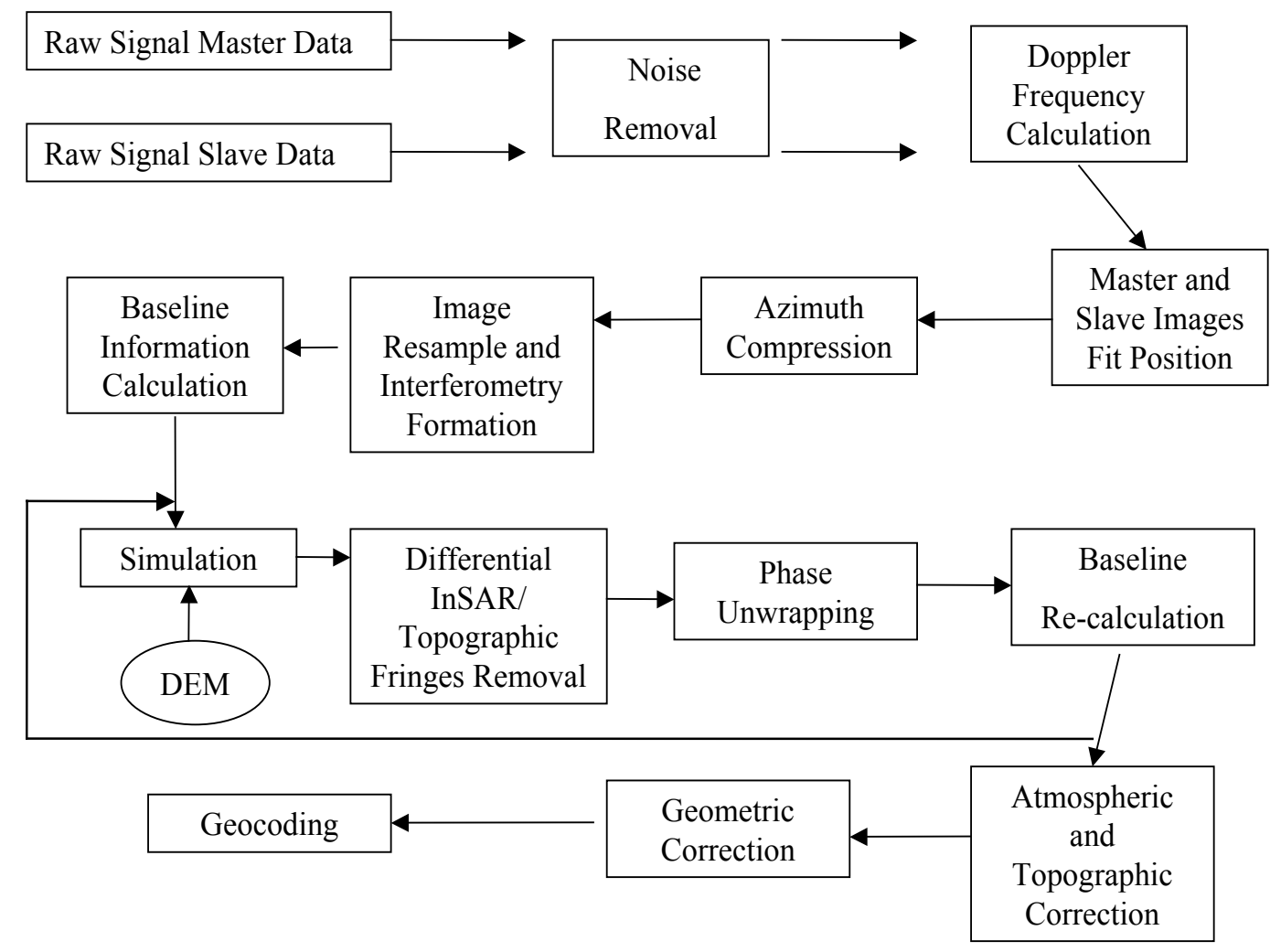

Figure 2. Interferometric SAR processing diagram based on GSISAR processing software [3] 
The software that developed by Mikio TOBITA (Geographical Survey Institute, Japan) was used to process the SAR data. With simple line command on linux operating system, GSISAR has capability to conservation phase and was designed to be interactive and familiarize to user.

\section{Results}

\section{A. Data pair}

Two pairs of data with convenient distance of baseline was selected to applied for InSAR processing.

Table 4.1. Two pairs of data used for Kanto Plain analyses

\begin{tabular}{|c|c|c|}
\hline Pair & Master & Slave \\
\hline 1 & $1995 / 03 / 14$ & $1997 / 12 / 20$ \\
\hline 2 & $1996 / 01 / 16$ & $1998 / 07 / 28$ \\
\hline
\end{tabular}

Single look complex image for each scene was taken for processing the data. Surface areas of approximately $75 \mathrm{Km}$ x $75 \mathrm{Km}$ was indentified by a location in latitude and longitude by date with pixel spacing of $8.7 \mathrm{~m}$ at slant range and $4.9 \mathrm{~m}$ at azimuth. Only suitable pairs for SAR interferometry were chosen those where the distance are short in baseline perpendicular $(\mathrm{Bp})$ and the acquisition interval. Table 4.1 shows the prioritized and selected data. Two-pass method was applied to generate the interferogram of the two pairs of data.

B. Interferometry

\begin{tabular}{c|c|c|c|}
\multirow{2}{*}{ Pair } & Date & $\begin{array}{c}\text { Baseline } \\
(\mathrm{m})\end{array}$ & $\begin{array}{c}\text { Period of days } \\
\text { day }\end{array}$ \\
\hline 1 & $1995 / 03 / 14-1997 / 12 / 20$ & 178 & 994 \\
\hline 2 & $1996 / 01 / 16-1998 / 07 / 28$ & 216 & 913 \\
\hline
\end{tabular}
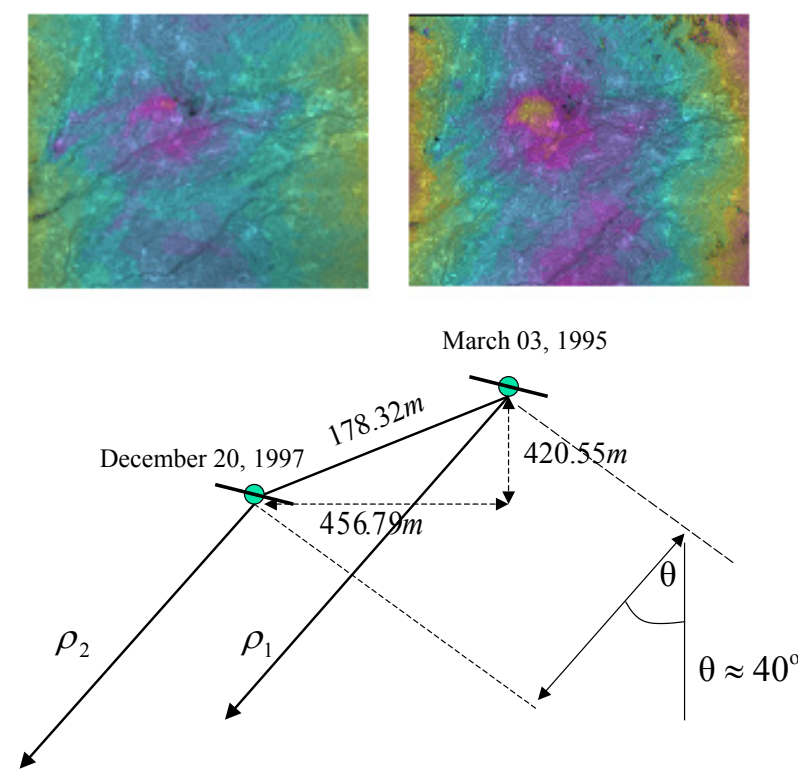

Figure 3. Geometry of JERS-1 orbits used on pairs of Kanto plain analyses
Pair 1

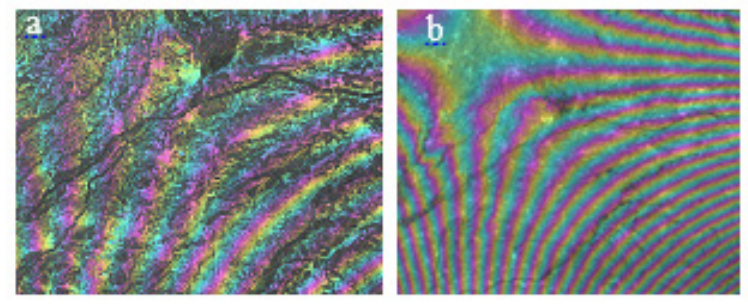

Pair 2
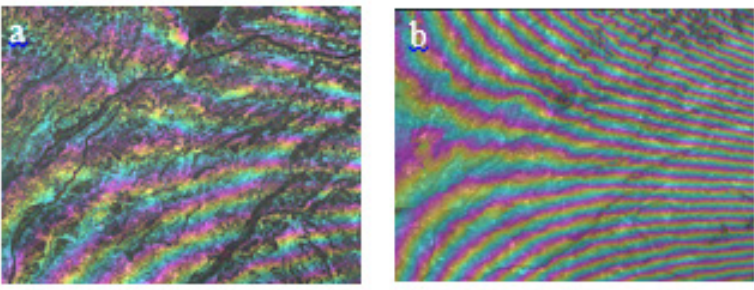

Figure 4. An interferomegram with good coherence is shown by pair1 and pair 2 before (a) and after (b) first topographic removal

\section{Phase Unwrapping}

Both pair 1 and pair 2 have a good correlation between master and slave image. Since correlation is an index of phase stability, correlation is an important factor in the interferometric technique. The good correlation or coherence leads to both pair 1 and pair 2 to be able to unwrap the phase after generate simulated interferogram based on DEM.
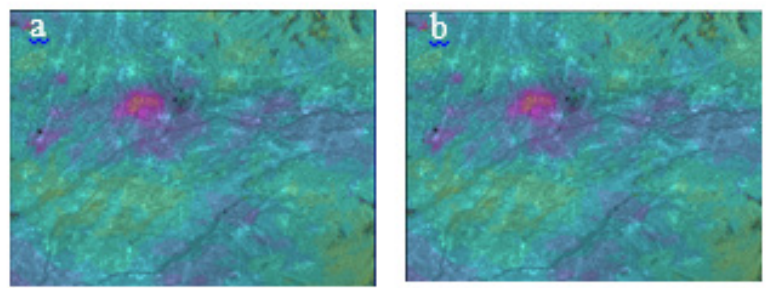

Figure 5. Interferogram of Kanto Plain area after phase unwapping process of pair 1(a) and pair 2(b)

\section{Kam aboko Phase}

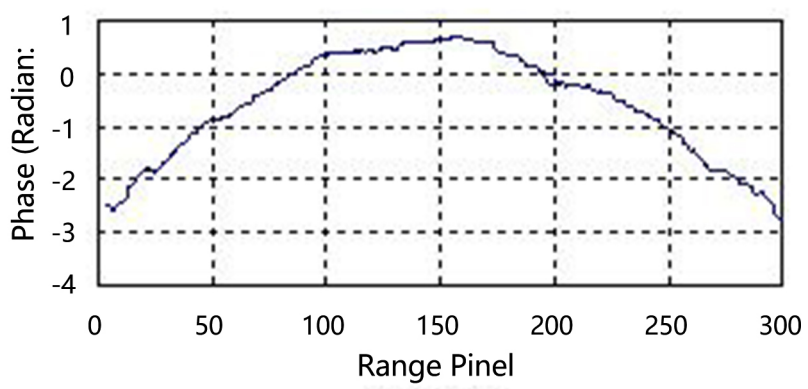

Figure 6. Phase sampling result of 1996/01/16-1998/07/28 pair, the curve is look like Japanese fish sausage "kamaboko", then called kamaboko phase [5] 
Since baseline components information is not correct, baseline components calculated from raw data cannot be used for accurate calculation. Consequently, "kamaboko" phase will remains at image after phase unwrapping process. Therefore, this "kamaboko" phase need to be removed to get the accurate baseline information.

\section{Atmospheric Correction}

Because of tropospheric variations, such as pressure and temperature, also might be expected to induce distortions, it is important to handling atmospheric correction to each image.

Figure 7 Inteferogram after atmospheric correction processing

\section{E. Subsidence of Kanto Area}

Figure 7 shows strong differential phase after the last phase unwrapping processing. Since topographic fringes have been removed, the variations here are related to surface change. There are various kinds of possibilities to these surface deformations in urban area like Kanto Plain. Land development is the highest possibility that made the surface change. Land subsidence due to ground water extraction for drinking water supply, agricultural use, and industrial use may cause surface change as well. Both pair 1 and pair 2 are relatively has the same period of different times, 2 years. Therefore, the images show the subsidence that occurred between to epoch of master and slave image that range different about 2 years. A full cycle of color change in the interferograms signifies a change of range by one-half wavelength of radar signal $(\lambda / 2=11.8 \mathrm{~cm})$.
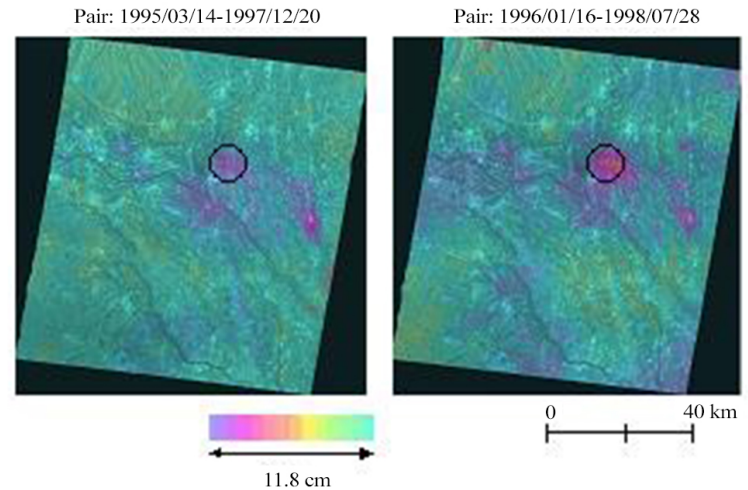

Figure 7. Geocoded of differential interferogram of 1995/03/14-1997/12/20 pair (a) and 1996/01/16-1998/07/28 pair. (b). Cycled area is area with maximum subsidence

Cycled area in figure 7 is the maximum subsidence of each data pair. Pair $1(1995 / 03 / 14-1997 / 12 / 20)$ has one of fringes cycle, while pair $2(1996 / 01 / 16-1998 / 07 / 28)$ has one until one-half of fringes cycle. Based on these fringes cycle, phase changed on the cycled area are caused by subsidence with vertical change range between 3.5-12.8 $\mathrm{cm}$ for pair 1 and $2.5-14.2 \mathrm{~cm}$.

Figure 7 shows that the area distribution of subsidence is a little different between two pairs. It means that the subsidence process developed and expanded over the year
1995 and 1998. It can be seen that almost center part of the area of pair 2 image has change in phase and this phase change area larger than phase change area of pair 1 . And at the south part of the area (Saitama prefecture), there is also a significant change in color cycle, while pair 1 is not.

Over the analyzed area, both pair 1 and pair 2, the surface deformation was only related to subsidence process, in other words, there is no surface arising or uplift of surface. It signed by color phase changes correspond from zero to minus values.

\section{F. Comparison with field measurements}

To estimate the accuracy of subsidence measurement from InSAR technique, the map result from InSAR technique then compare to field measurement in this case ground leveling measurement. Leveling has been conducted in Kanto Plain area systematically on year 2002[6]. It is reported the subsidence of the area between 1990 until 1994. The result is showed by figure 4.2.6-1. From his report, it can be concluded that the maximum subsidence was about $15 \mathrm{~cm}$ in about 4 years. And this maximum subsidence occurred in the center of the area, lies at Nogi-cho of Tochigi prefecture.

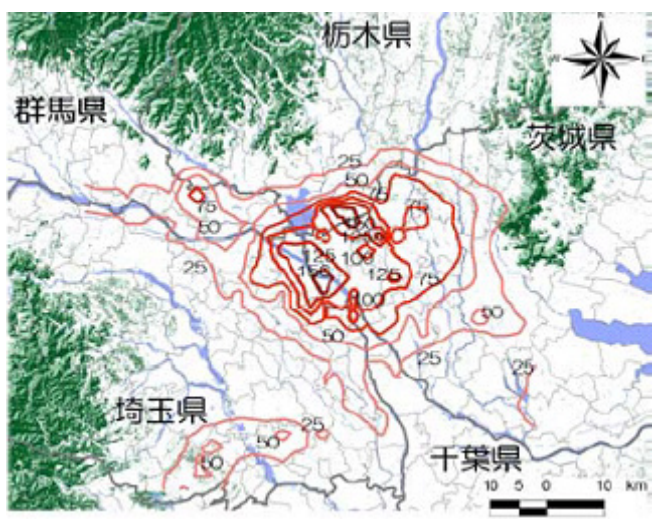

Figure 8. Subsidence based on leveling measurement from 1990-1994[6]

For the distribution of subsidence of Kanto Plain, there is a good agreement between InSAR technique result and ground water leveling measurement result. The area with maximum subsidence acquired from InSAR technique both pair 1 and pair 2 also being the same with leveling measurement area, it lies at Nogi-cho of Tochigi prefecture (cycled area on InSAR imagery showed by figure 4.2.4-1).

However, there is a difference in subsidence rate per year of leveling measurement and InSAR technique. It can be caused by the difference periods of the data used to calculate for the measurement. The leveling measurements was used data from 1990-1994, while InSAR technique used periods from year 1995-1997 and 1996-1998. However, from these three data, it can be concluded that the subsidence rate was going up over the year 1990 until 1998, with rate subsidence per year from $3.75 \mathrm{~cm}$ per year from 1990 until 1994, became $7.1 \mathrm{~cm}$ per year from 1996 until 1998. 


\section{Conclusions}

Two pairs data were used for detecting land subsidence performed a good correlation and good interferometry then the surface change of Kanto plain area could be detect by the pairs [7]. From pair 1 (1995/03/14-1997/12/20), processing result can be concluded that the maximum subsidence of Kanto Plain between two years is about $12.8 \mathrm{~cm}$; while from pair 2 $(1996 / 01 / 16-1998 / 07 / 28)$, it is about $14.2 \mathrm{~cm}$. These results are compared to subsidence that measured from ground water measurement from earlier researcher [8]. Quantitatively, there is a good agreement between the InSAR technique and leveling measurement result. However, this result has to be compared with another data with the same periods of measurement to get an accurate and satisfactorily result.

\section{REFERENCES}

[1] Wang, X., Wang, Y., Ge, J., Wu, P., \& Huang, T. (2018). Applying Building Information Modelling Plus-the Practice of Shanghai Shipping Service Complex. Review of Industrial Engineering Letters, 4(2), 21-35.

[2] Kumar, G., \& Bhatia, P. K. (2015). A detailed analysis of software cost estimation using COSMIC-FFP. PAK Publishing Group J. Rev Comput. Eng. Res, 2(2), 39-46.

[3] Tobita, M., (2003), "Development of SAR Interferometry Analyses and its Application to Crustal Deformation Study", Journal of the Geodetic Society of Japan, Vol. 49, no.1, pp $1-23$.

[4] Rosen. P. A, Hensley. S, Ian r. Joughin, Madsen, and Goldstein, R. M., Synthetic Aperture Radar Interferometry”, Proceedings of the ieee, vol. 88, no. 3, March 2000.

[5] Tobita, M., Fujiwara, S., Ozawa, S., Rosen, P.A, Fielding, E.J., Werner, C.L., Murakami, M., Nakagawa, H., Nitta, K., and M. Murakami, (1998), "Deformation of the 1995 North Sakhalin earthquake detected by JERS-1/SAR interferometry", Earth Planets Space, 50, 313-325.

[6] Murakami, S., Yasuhara, K., Mochizuki, N. and Hayano, T., (2001), "Spatial Analysis of Groundwater and Land Subsidence in the Northern Kanto Plane", Journal of Ground Water Technology Vol.43 No.10, pp. 11-22.

[7] Jabarullah, N. H. (2019) Production of olefins from syngas over A12O3 supported Ni and $\mathrm{Cu}$ nano-catalysts, Petroleum Science and Technology, DOI: 10.1080/10916466.2018.1547758.

[8] Jabarullah, N.H. \& Othman, R. (2018) Steam reforming of shale gas over $\mathrm{Al} 2 \mathrm{O} 3$ supported $\mathrm{Ni}-\mathrm{Cu}$ nano-catalysts, Petroleum Science and Technology, DOI: 10.1080/10916466.2018.1547759. 